\title{
Effect of Polydeoxyribonucleotide on Lipopolysaccharide and Sevoflurane-Induced Postoperative Cognitive Dysfunction in Human Neuronal SH-SY5Y Cells
}

\author{
Hyungmo Jeong, ${ }^{1, \star}$, Jun-Young Chung ${ }^{2, *}$, Il-Gyu Ko ${ }^{3}$, Sang-Hoon Kim³ , Jun-Jang Jin ${ }^{3}$, Lakkyong Hwang ${ }^{3}$, Eun Jin Moon², \\ Bong Jae Lee', Jae Woo $\mathrm{Yi}^{2}$ \\ ${ }^{1}$ Department of Anesthesiology and Pain Medicine, Eutteum Hospital, Paju, Korea \\ ${ }^{2}$ Department of Anesthesiology and Pain Medicine, Kyung Hee University Hospital at Gangdong, College of Medicine, Kyung Hee University, Seoul, Korea \\ ${ }^{3}$ Department of Physiology, College of Medicine, Kyung Hee University, Seoul, Korea
}

Purpose: Postoperative cognitive dysfunction (POCD) is a complication of surgery characterized by acute cognitive dysfunction, memory impairment, and loss of attention. The effect of polydeoxyribonucleotide (PDRN) on the POCD environment induced by lipopolysaccharide (LPS) and sevoflurane exposure were investigated in human neuronal SH-SY5Y cells.

Methods: The 3-(4,5-dimethylthiazol-2-yl)-2,5-diphenyltetrazolium bromide (MTT) and WST-8 assays were performed to determine cell viability. Cyclic adenosine-3,5'-monophosphate (cAMP), tumor necrosis factor (TNF)- $\alpha$, interleukin (IL)- $1 \beta$, and IL-6 concentrations were measured using enzyme-linked immunoassay (ELISA). Immunocytochemistry was performed for vascular endothelial growth factor (VEGF) and brain-derived neurotrophic factor (BDNF), and western blotting for TNF- $\alpha$, IL-1 $\beta$, IL-6, and cAMP response element-binding protein (CREB).

Results: Induction of the POCD environment reduced cell viability in the MTT and WST-8 assays. PDRN treatment reduced TNF- $\alpha$, IL- $1 \beta$, and IL- 6 expression in POCD conditions, and significantly increased cAMP concentrations and the p-CREB/ CREB ratio. PDRN treatment activated adenosine $\mathrm{A}_{2 \mathrm{~A}}$ receptors and then increased the expression of VEGF and BDNF, which had been reduced by LPS and sevoflurane exposure.

Conclusions: PDRN treatment showed a therapeutic effect on the LPS and sevoflurane-induced POCD environment. PDRN was shown to have an excellent therapeutic effect on POCD, not only by promoting rapid anti-inflammatory effects in damaged cells, but also by enhancing the expression of BDNF and VEGF.

Keywords: Postoperative cognitive dysfunction; Polydeoxyribonucleotides; Pro-inflammatory cytokine

- Fund/Grant Support: This study was supported by the Ministry of Education of the Republic of Korea and the National Research Foundation of Korea (NRF-2018R1D1A1B07048308).

- Research Ethics: This study was approved by the Institutional Care and Use Committee of Kyung Hee University (KHUASP [SE]-18-127).

- Conflict of Interest: No potential conflict of interest relevant to this article was reported.

\section{- HIGHLIGHTS}

- POCD is a complication of surgery characterized by acute cognitive dysfunction and memory impairment.

- PDRN promoted anti-inflammatory effects in POCD conditions.

- PDRN enhanced the expression of BDNF and VEGF in POCD conditions.

Corresponding author: Jae Woo Yi (iD https://orcid.org/0000-0001-6474-5624 Department of Anesthesiology and Pain Medicine, Kangdong Kyung Hee Hospital, College of Medicine, Kyung Hee University, 892 Dongnam-ro, Gangdong-gu, Seoul 05278, Korea

E-mail: mdyjchk@khu.ac.kr / Tel: +82-2-440-6191 / Fax: +82-2-440-7808

Submitted: October 8, 2019 / Accepted after revision: November 10, 2019

${ }^{\star}$ Hyungmo Jeong and Jun-Young Chung contributed equally to this study as co-first authors. 


\section{INTRODUCTION}

As global healthcare trends improve, the aged population has steadily increased. However, as the population ages, surgery is more often performed in older patients and those with a high accompanying complication rate. Many older patients experience postoperative cognitive dysfunction (POCD) [1], which is a surgical complication characterized by acute cognitive dysfunction, memory impairment, and loss of attention [2]. POCD reduces the quality of life of patients, seriously increases the cost burdens of medical care, and also raises the risk for mortality. In addition, POCD can persist for a long time, potentially leading to severe degenerative brain diseases such as dementia $[1,3]$.

Central nervous system (CNS) inflammation caused by anesthesia or surgery has been reported to play an important role in the development of POCD [4,5]. In particular, anesthesia and surgery have been shown to increase brain concentrations of interleukin (IL)- $1 \beta$ and IL-6, leading to neuronal cell apoptosis and to the release of tumor necrosis factor (TNF)- $\alpha[6,7]$. Learning and memory function have also been found to be impaired by surgery and anesthesia in experimental animals, accompanied by upregulation of pro-inflammatory cytokine levels in both the blood and brain $[8,9]$. Therefore, there is a need for a pharmacological treatment method based on a new understanding of the pathogenesis of POCD.

Polydeoxyribonucleotide (PDRN) extracted from salmon sperm stimulates tissue repair in chronic wounds and burns [10]. PDRN activates adenosine $A_{2 \mathrm{~A}}$ receptors to stimulate vascular endothelial growth factor (VEGF) expression, resulting in reduced ischemic damage and increased oxygen supply [11]. PDRN also exerts anti-inflammatory effects by inhibiting the production of pro-inflammatory cytokines such as TNF- $\alpha$ and IL-6 and enhancing the production of anti-inflammatory cytokines such as IL-10 $[12,13]$. However, although the clinical effect of PDRN dramatically inhibits inflammation in various diseases, its effects in the CNS remain unknown, and there have been no reports of the efficacy of PDRN for improving POCD.

In this study, human neuronal SH-SY5Y cells were used to investigate the effect of PDRN treatment on a POCD environment induced by lipopolysaccharide (LPS) and sevoflurane exposure. In this study, MTT and WST-8 assays were performed to determine cell viability. Cyclic adenosine-3,5'-monophosphate (cAMP), TNF- $\alpha$, IL- $1 \beta$, and IL- 6 concentrations were measured using enzyme-linked immunoassay (ELISA). Immunocytochemistry was performed for VEGF and brain-derived neurotrophic factor (BDNF), and western blotting was performed for TNF- $\alpha$, IL-1 $\beta$, IL- 6 , and cAMP response elementbinding protein (CREB).

\section{MATERIALS AND METHODS}

\section{Cell Culture}

Human neuroblastoma SH-SY5Y cells were purchased from Korean Cell Line Bank (KCLB, Seoul, Korea). SH-SY5Y cells were maintained in RPMI1640 medium supplemented with heat-inactivated $10 \%$ fetal bovine serum, $1 \%$ streptomycin, and penicillin. The cells were incubated under the conditions of $5 \%$ $\mathrm{CO}_{2}$ in a $37^{\circ} \mathrm{C}$ incubator. This study was approved by the Institutional Care and Use Committee of Kyung Hee University (KHUASP [SE]-18-127).

\section{Induction of the POCD Environment and PDRN Treatment}

The POCD environment was induced according to the methods described in a previous study [14]. Considering that POCD was induced using an inflammatory and an inhalation anesthetic, SH-SY5Y cells were plated at a density of $1 \times 10^{5}$ cells/well in 96well plates. The culture medium was then changed to serum-free with 1- $\mu \mathrm{g} / \mathrm{mL}$ LPS (Escherichia coli serotype 026: B6; Sigma Chemical Co., St. Louis, MO, USA) prior to PDRN treatment. After LPS treatment, the cell culture was treated with PDRN (PharmaResearch Product, Gangneung, Korea) at concentrations of 4,8 , and $16 \mu \mathrm{g} / \mathrm{mL}$. Immediately after PDRN treatment, the plates were placed in an anesthetic acrylic chamber and exposed to $4 \%$ sevoflurane with $30 \% \mathrm{O}_{2}$ and $70 \% \mathrm{~N}_{2}$ gas for 1 hour.

\section{MTT Assay}

After induction of the POCD environment and PDRN treatment, MTT solution (Sigma Chemical Co.) was immediately added to the drug-treated well plate at a final concentration of $0.05 \mathrm{mg} / \mathrm{mL}$ after drug treatment. The plate was placed in a rigid chamber and exposed to $4 \%$ sevoflurane gas for 1 hour. Dimethyl sulfoxide (Sigma Chemical Co.) $(100 \mu \mathrm{L})$ was added and shaken for 15 minutes to dissolve the MTT formazan crystals that formed after anesthetic exposure. The wells in the plates were analyzed using an ELISA plate reader (Thermo Fisher Scientific Inc., Fair Lawn, NJ, USA) at a wavelength of $570 \mathrm{~nm}$.

\section{WST-8 Assay}

Immediately after induction of the POCD environment and PDRN treatment, $10 \mu \mathrm{L}$ of WST-8 kit solution (Biomax, Seoul, 
Korea) was added to each well. After incubation at $37^{\circ} \mathrm{C}$ for 1 hour, the WST-8-reduced wells were placed in an ELISA microplate reader (Thermo Fisher Scientific Inc.) and the optical density was measured at a wavelength of $450 \mathrm{~nm}$.

\section{ELISA Assay}

Cell culture supernatants were collected for ELISA analysis to measure levels of TNF- $\alpha$, IL-6, IL-1 $\beta$, and cAMP (Abcam, Cambridge, UK). After induction of the POCD environment and PDRN treatment, the cell supernatant was centrifuged at $1,000 \times g$ at $4^{\circ} \mathrm{C}$ for 20 minutes to remove insoluble impurities. Precoated well plates were washed before adding standard, sample, and control wells. Standards, controls, and samples were added to each well, incubated at $37^{\circ} \mathrm{C}$ for 90 minutes, and the plates washed. Working solutions with biotin-labeled antibodies were added to each well and incubated at $37^{\circ} \mathrm{C}$ for 60 minutes. Working solutions with streptavidin conjugates were incubated in each well for 30 minutes at $37^{\circ} \mathrm{C}$. TMB substrate was then added and incubated at $37^{\circ} \mathrm{C}$ for 20 minutes. After incubation, the solution was analyzed using a microplate reader (Thermo Fisher Scientific Inc.) at a wavelength of $450 \mathrm{~nm}$.

\section{Western Blot}

After induction of the POCD environment and PDRN treatment, to obtain protein samples, SH-SY5Y cells were washed once with phosphate-buffered saline (PBS) to remove the medium. Radio immunoprecipitation assay buffer with $1 \mathrm{mM}$ PMSF (Cell Signaling Technology, Denver, CO, USA) was added to a $100-\mathrm{mm}$ dish and incubated for 5 minutes on ice. Cells were collected in 1.5-mL microcentrifuge tubes and briefly sonicated. Cell lysates were centrifuged at $14,000 \times g$ at $4^{\circ} \mathrm{C}$ for 20 minutes and the supernatants were collected. Protein $(20 \mu \mathrm{g})$ was loaded onto a $12 \%$ sodium dodecyl sulfate-polyacrylamide gel electrophoresis gel and electrotransferred to a nitrocellulose membrane. The primary antibodies were mouse TNF- $\alpha$ antibody, mouse IL- 6 antibody, mouse $\beta$-actin antibody, rabbit IL- 6 antibody, rabbit CREB antibody, and rabbit phosphorylated (p)-CREB antibody (Santa Cruz Biotechnology, Santa, CA, USA). Secondary anti-mouse and anti-rabbit antibodies were reacted at room temperature (RT) for 1 hour. The membrane was detected by an enhanced chemiluminescence detection kit (Bio-Rad, Hercules, CA, USA). The development band was quantified by Image Pro Plus version 6.0 (Media Cybernetics Inc., Silver Spring, MD, USA).

\section{Immunofluorescence}

To perform the immunofluorescence assay, the treated wells were washed with PBS and fixed at RT for 30 minutes in 4\% paraformaldehyde. After blocking with 3\% normal goat serum and $1 \%$ bovine serum albumin (Vector Laboratory, Burlingame, CA, USA) for 1 hour, the well plate was incubated with primary antibodies to BDNF (1:500; Santa Cruz Biotechnology) and VEGF (1:500, Santa Cruz Biotechnology) at $4^{\circ} \mathrm{C}$ overnight. After plate washes, the plates were incubated with secondary Alexa Fluor 488-goat anti-rabbit IgG (1:400; Vector Laboratory) and Alexa Fluor 594-goat anti-mouse IgG (1:400; Vector Laboratory) antibodies for 1.5 hours at RT. Cells were counterstained with a $4^{\prime}, 6$-diamidino-2-phenylindole mounting solution (Vector Laboratory), and slide images were analyzed by fluorescence microscopy.

\section{Statistical Analysis}

Statistical analysis was performed using 1-way analysis of variance followed by the Duncan post hoc test using IBM SPSS Statistics ver. 23.0 (IBM Co., Armonk, NY, USA) and the results were expressed as mean \pm standard error of the mean. Significance was set to $\mathrm{P}<0.05$.

\section{RESULTS}

\section{Cell Viability Under POCD Conditions}

To determine the cytotoxicity of POCD and how it was affected by PDRN, the viability of cells in POCD conditions in SHSY5Y cells was measured using the MTT and WST- 8 assays. As shown in Fig. 1, cell viability in the MTT and WST-8 assays was significantly decreased by the induction of POCD conditions $(\mathrm{P}<0.05)$. However, PDRN treatment showed an enhancing effect on the viability of human neuronal SH-SY5Y cells in POCD conditions $(\mathrm{P}<0.05)$. A PDRN concentration of $8 \mu \mathrm{g} / \mathrm{mL}$ more potently improved cell viability.

\section{Pro-inflammatory Cytokines in POCD Conditions}

To determine the effect of PDRN on the expression of pro-inflammatory cytokines in SH-SY5Y cells in POCD conditions, TNF- $\alpha$, IL- $1 \beta$, and IL- 6 expressions were measured using ELISA. As presented in Fig. 2, TNF- $\alpha$, IL-1 $\beta$, and IL-6 expression was significantly increased by induction of POCD $(\mathrm{P}<0.05)$. However, PDRN treatment suppressed TNF- $\alpha$, IL-1 $\beta$, and IL-6 expression in the SH-SY5Y cells in POCD conditions. A PDRN concentration of $8 \mu \mathrm{g} / \mathrm{mL}$ more potently suppressed the expres- 

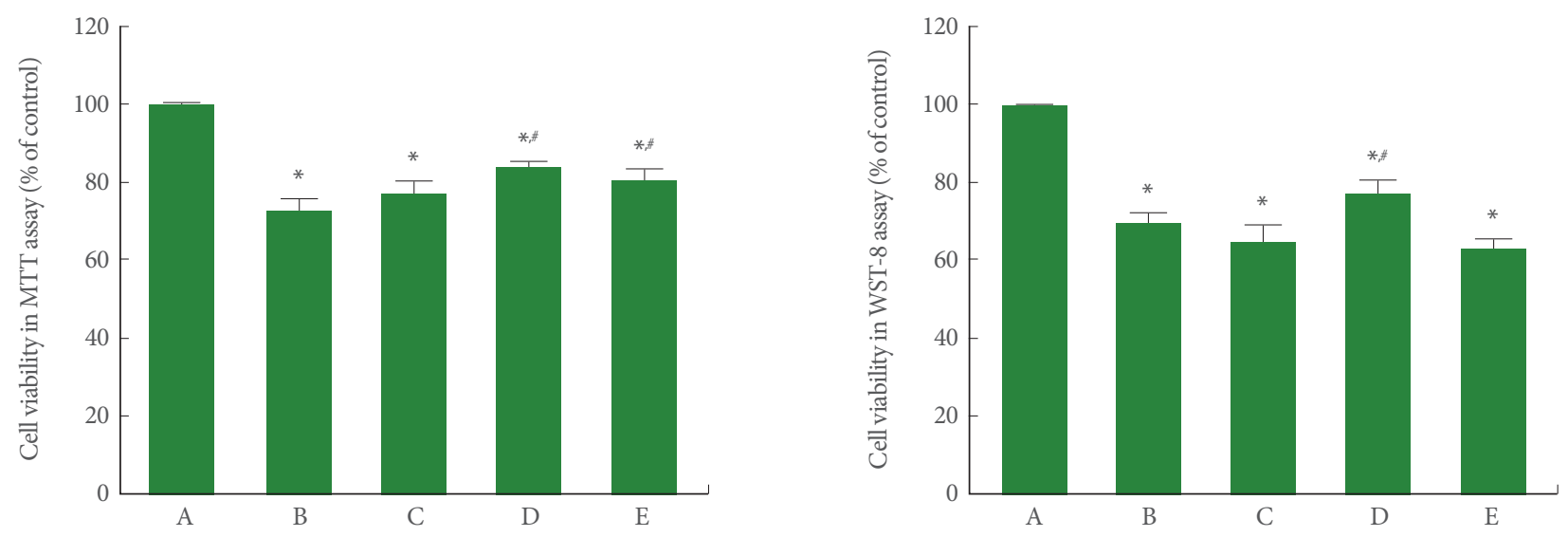

Fig. 1. Cell viability in conditions of postoperative cognitive dysfunction (POCD) in human neuronal SH-SY5Y cells. Left panel: The cells were stained using the 3-(4,5-dimethylthiazol-2-yl)-2,5-diphenyltetrazolium bromide (MTT) method. Right panel: The cells were stained using the WST-8 method. A, control group; B, POCD-induced group; C, POCD-induced and 4- $\mu \mathrm{g} / \mathrm{mL}$ PDRN-treated group; D, POCD-induced and 8- $\mu \mathrm{g} / \mathrm{mL}$ PDRN-treated group; E, POCD-induced and 16- $\mathrm{gg} / \mathrm{mL}$ PDRN-treated group. *P $<0.05$ compared to the control group. ${ }^{*} \mathrm{P}<0.05$ compared to the POCD-induced group.


sion of pro-inflammatory cytokines.

\section{Pro-inflammatory Cytokines in POCD Conditions}

To determine the effect of PDRN treatment on the expression

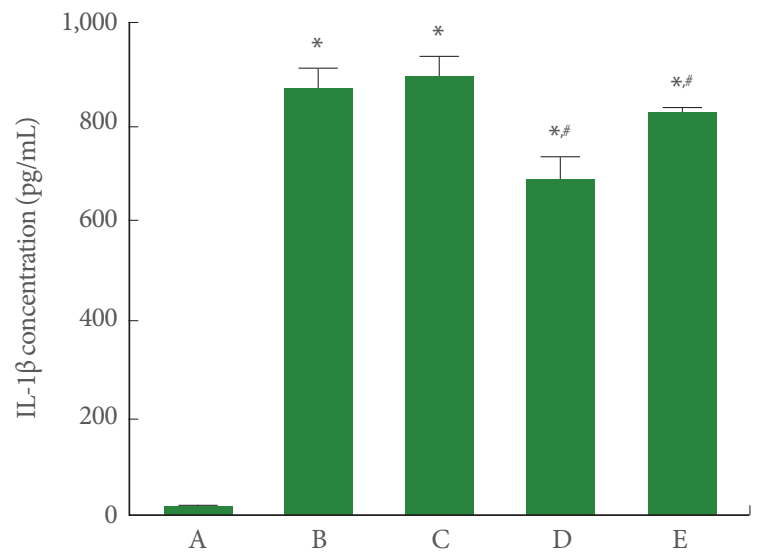

Fig. 2. Enzyme-linked immunoassay (ELISA) detection of tumor necrosis factor (TNF)- $\alpha$, interleukin (IL)- $1 \beta$, and IL- 6 expression in conditions of postoperative cognitive dysfunction (POCD) in human neuronal SH-SY5Y cells. Upper left panel: TNF- $\alpha$ expression determined using ELISA. Upper right panel: IL-1 $\beta$ expression determined using ELISA. Lower panel: IL-6 expression determined using ELISA. A, control group; B, POCD-induced group; C, POCD-induced and $4-\mu \mathrm{g} / \mathrm{mL}$ PDRN-treated group; D, POCD-induced and 8- $\mu \mathrm{g} / \mathrm{mL}$ PDRNtreated group; E, POCD-induced and $16-\mu \mathrm{g} / \mathrm{mL}$ PDRN-treated group. ${ }^{\star} \mathrm{P}<0.05$ compared to the control group. ${ }^{*} \mathrm{P}<0.05 \mathrm{com}$ pared to the POCD-induced group.

of pro-inflammatory cytokines in SH-SY5Y cells in POCD conditions, TNF- $\alpha$, IL- $1 \beta$, and IL- 6 expression was measured by western blotting, and the results are presented in Fig. 3 . TNF- $\alpha$, IL- $1 \beta$, and IL- 6 expression was significantly increased 

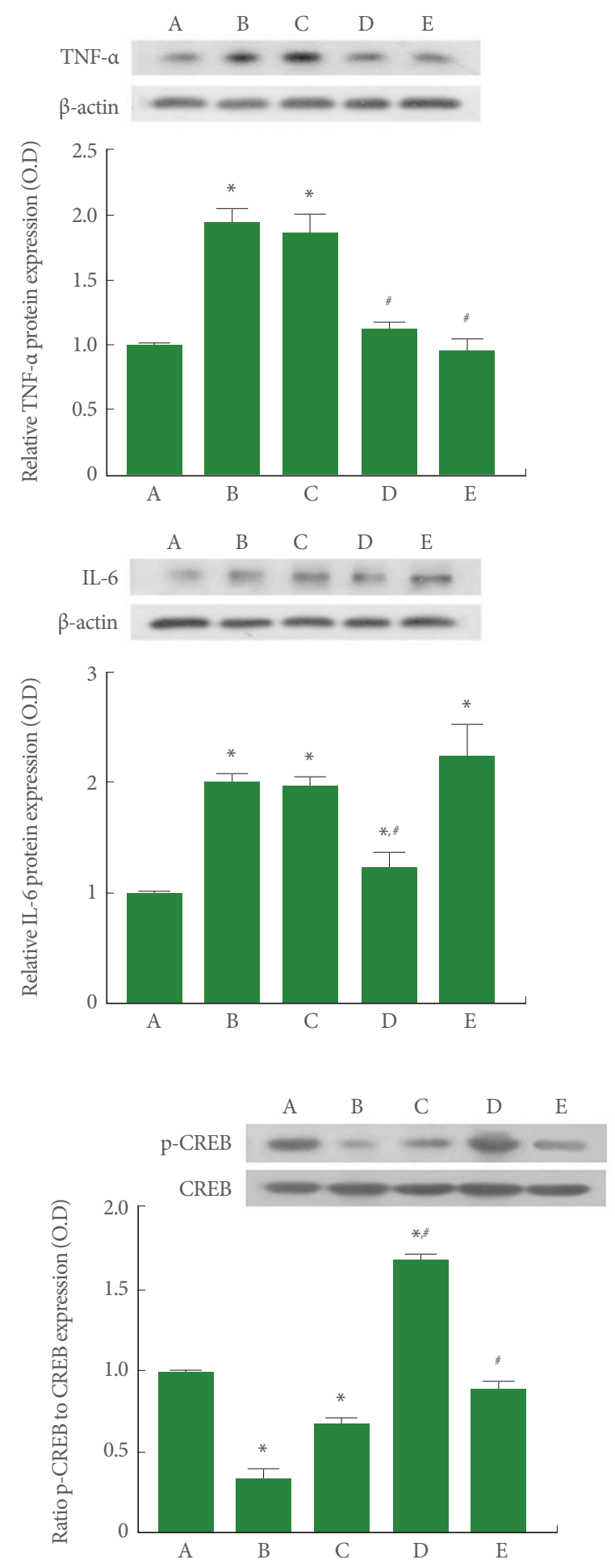

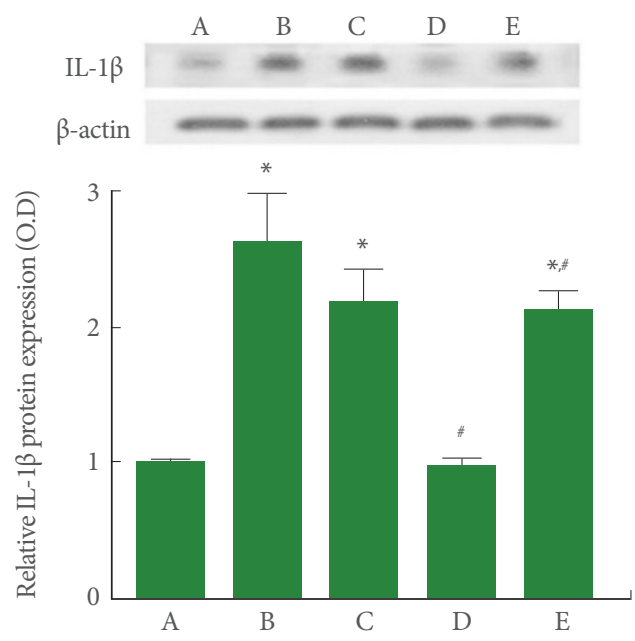

Fig. 3. Western blot analysis of tumor necrosis factor (TNF)- $\alpha$, interleukin (IL)-1 $\beta$, and IL-6 expression in conditions of postoperative cognitive dysfunction (POCD) in human neuronal SH-SY5Y cells. Upper left panel: The relative expression of TNF- $\alpha$ determined using western blotting. Upper right panel: The relative expression of IL- $1 \beta$ determined using western blotting. Lower panel: The relative expression of IL- 6 determined using western blotting. A, control group; B, POCD-induced group; C, POCD-induced and $4-\mu \mathrm{g} / \mathrm{mL}$ PDRN-treated group; D, POCD-induced and $8-\mu \mathrm{g} / \mathrm{mL}$ PDRN-treated group; E, POCD-induced and $16-\mu \mathrm{g} / \mathrm{mL}$ PDRN-treated group. ${ }^{\star} \mathrm{P}<0.05$ compared to the control group. ${ }^{*} \mathrm{P}<0.05$ compared to the POCD-induced group.



Fig. 4. Phosphorylated cyclic adenosine-3,5'-monophosphate (cAMP) response element-binding protein (p-CREB)/CREB ratio and cAMP expression under conditions of postoperative cognitive dysfunction (POCD) in human neuronal SH-SY5Y cells. Left panel: The relative expression of $\mathrm{p}-\mathrm{CREB}$ and CREB determined by western blotting. Right panel: cAMP expression determined using enzyme-linked immunoassay. A, control group; B, POCD-induced group; C, POCD-induced and $4-\mu \mathrm{g} / \mathrm{mL}$ PDRN-treated group; D, POCD-induced and $8-\mu \mathrm{g} / \mathrm{mL}$ PDRN-treated group; E, POCD-induced and $16-\mu \mathrm{g} / \mathrm{mL}$ PDRN-treated group. ${ }^{\star} \mathrm{P}<0.05$ compared to the control group. ${ }^{*} \mathrm{P}<0.05$ compared to the POCD-induced group. 

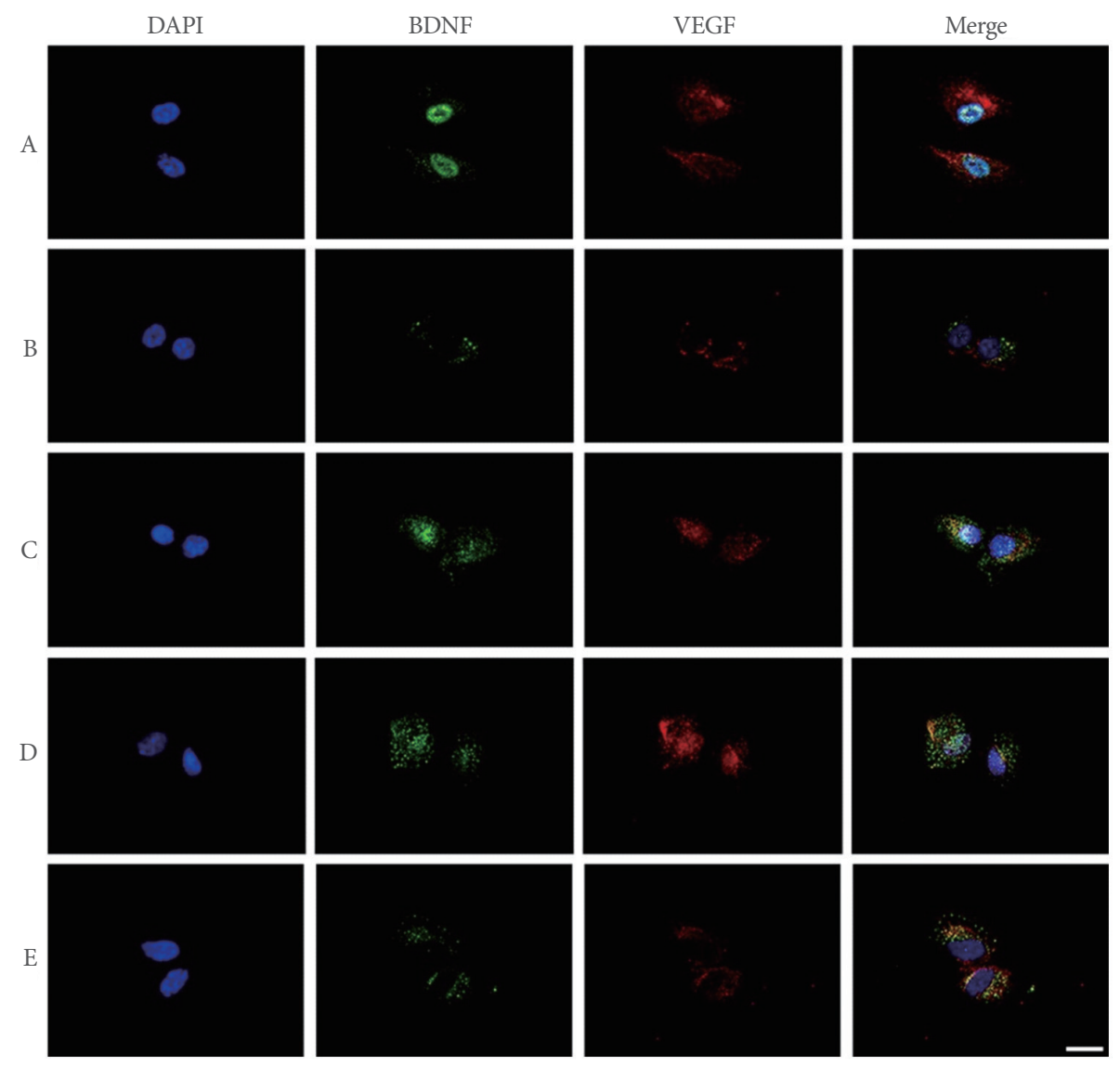

Fig. 5. Brain-derived neurotrophic factor (BDNF) and vascular endothelial growth factor (VEGF) expression in conditions of postoperative cognitive dysfunction (POCD) in human neuronal SH-SY5Y cells. SH-SY5Y cells were immunostained for BDNF (green) and VEGF (red). Cells were counterstained with 4'-6-diamidino-2-phenylindole (DAPI, blue). Scale bar represents $100 \mu \mathrm{m}$. A, control group; B, POCD-induced group; C, POCD-induced and 4- $\mu \mathrm{g} / \mathrm{mL}$ PDRN-treated group; D, POCD-induced and 8- $\mu \mathrm{g} / \mathrm{mL}$ PDRNtreated group; E, POCD-induced and $16-\mu \mathrm{g} / \mathrm{mL}$ PDRN-treated group.

by induction of POCD $(\mathrm{P}<0.05)$. However, PDRN treatment suppressed TNF- $\alpha$, IL-1 $\beta$, and IL-6 expression in the SH-SY5Y cells in POCD conditions. A PDRN concentration of $8 \mu \mathrm{g} / \mathrm{mL}$ more potently suppressed the expression of pro-inflammatory cytokines.

\section{p-CREB/CREB Ratio and cAMP Expression in POCD Conditions}

To determine the effect of PDRN treatment on the ratio of $\mathrm{p}$ CREB to CREB in SH-SY5Y conditions in POCD conditions, the $\mathrm{p}$-CREB to CREB ratio was measured by western blot analysis. Furthermore, to determine the effect of PDRN treatment on the concentration of CAMP in SH-SY5Y in POCD conditions, cAMP concentrations were determined by ELISA. The results are presented in Fig. 4 . The $\mathrm{p}-\mathrm{CREB} / \mathrm{CREB}$ ratio and
cAMP expression were significantly increased by induction of POCD $(\mathrm{P}<0.05)$. However, PDRN treatment suppressed the $\mathrm{p}$ CREB/CREB ratio and cAMP expression in SH-SY5Y cells in POCD conditions $(\mathrm{P}<0.05)$. A PDRN concentration of $8 \mu \mathrm{g} / \mathrm{mL}$ more potently enhanced the $\mathrm{p}-\mathrm{CREB} / \mathrm{CREB}$ ratio and $\mathrm{CAMP}$ expression.

\section{Expression of BDNF and VEGF in POCD Conditions}

To determine the effect of PDRN treatment on BDNF and VEGF expression in SH-SY5Y cells in POCD conditions, BDNF and VEGF expression was measured using immunocytochemistry. As shown in Fig. 5, induction of the POCD environment by LPS and sevoflurane exposure decreased the expression of BDNF and VEGF compared to the control group. However, PDRN treatment enhanced BDNF and VEGF ex- 
pression in SH-SY5Y cells in POCD conditions.

\section{DISCUSSION}

After anesthesia, peripheral immune cells can participate in the inflammatory response in the hippocampus, causing POCD [15]. Inhalation anesthesia promotes neuronal cell apoptosis in animal models, reducing learning ability and memory $[4,16]$. Previous studies involving POCD showed that these changes were not only limited to the CNS, but, through urinary metabolites and other biomarkers, implicated the potential for systemic post operative dysfunctions, including voiding dysfunctions commonly seen following major surgeries $[17,18]$. In this study, human neuronal SH-SY5Y cells were treated with LPS to induce an inflammatory state and treated with an inhalation anesthetic, sevoflurane, to induce a POCD environment.

Elevated levels of pro-inflammatory cytokines in the hippocampus can impair synaptic function and lead to cognitive impairment $[19,20]$. Sevoflurane also induces the activation and release of inflammatory factors such as TNF- $\alpha$, IL-1 $\beta$, and IL-6 by astrocytes in the CNS $[4,21]$. The present study showed that the expression of TNF- $\alpha$, IL- $1 \beta$, and IL- 6 significantly increased after LPS treatment and sevoflurane exposure, suggesting that POCD is exacerbated by overproduction of these pro-inflammatory cytokines. While the pathophysiology of LPS on voiding function has traditionally been associated with local effects, this may also implicate a systemic and neurogenic central pathophysiology for bacterial inflammation to affect voiding [22]. For this reason, induction of the POCD environment by LPS treatment and sevoflurane exposure reduced cell viability in the MTT and WST- 8 assays. Thus, inhibition of pro-inflammatory cytokines may be a therapeutic principle for POCD. PDRN reduces the production of pro-inflammatory cytokines, including IL-1 $\beta$, IL-6, and TNF- $\alpha$ [13]. In this study, PDRN treatment reduced TNF- $\alpha$, IL-1 $\beta$, and IL- 6 expression in POCD conditions. Reduction of pro-inflammatory cytokines by PDRN plays an important role in the treatment of POCD.

Adenosine $\mathrm{A}_{2 \mathrm{~A}}$ receptors promote the phosphorylation of CREB through the cAMP-dependent protein kinase A (PKA) pathway, inhibiting the production of pro-inflammatory cytokines $[13,23]$. Thus, adenosine $\mathrm{A}_{2 \mathrm{~A}}$ receptor agonists are known to be effective in the treatment of inflammation-related diseases $[13,24]$. The CREB/BDNF pathway is known to be associated with spatial learning ability [25]. In this study, PDRN treatment significantly increased cAMP concentrations and the p-CREB/
CREB ratio, demonstrating that PDRN activates the cAMPPKA-CREB pathway.

BDNF is involved in learning ability and memory processes, and is also a critical molecule for neuroprotection [26,27]. BDNF and VEGF play an important role in restoring cognitive function and memory loss due to brain damage [28]. The present study showed that in human neuronal SH-SY5Y cells, the expression of BDNF and VEGF decreased after LPS and sevoflurane exposure for the environmental induction of POCD. These results indicate that BDNF and VEGF expression was reduced by the overproduction of pro-inflammatory cytokines following POCD induction.

Most of the actions on BDNF on excitatory plasticity are under the control of adenosine $A_{2 A}$ receptors [29]. Experimental data indicate that adenosine $\mathrm{A}_{2 \mathrm{~A}}$ receptor activation is critical to the function of neurotrophic receptors at synapses $[29,30]$. Likewise, VEGF expression is induced by stimulation of adenosine $A_{2 A}$ receptors [31], which are co-localized with $B D N F$ in the brain, and a functional interaction between adenosine $\mathrm{A}_{2 \mathrm{~A}}$ receptor stimulation and BDNF action has been proposed $[32,33]$. In this study, PDRN treatment activated adenosine $\mathrm{A}_{2 \mathrm{~A}}$ receptors and then increased the expression of VEGF and BDNF, which had been reduced by LPS and sevoflurane exposure. Inhibition of pro-inflammatory cytokines and increased levels of growth factors have been shown to improve damaged cells and eventually to increase cell viability in the POCD environment.

In conclusion, PDRN treatment showed a therapeutic effect on the LPS and sevoflurane-induced POCD environment. The excellent therapeutic effect of PDRN on POCD was exerted not only by promoting rapid anti-inflammatory effects in damaged cells, but also by enhancing the expression of BDNF and VEGF. Thus, PDRN may provide new directions for the treatment of POCD.

\section{AUTHOR CONTRIBUTION STATEMENT}

- Full access to all the data in the study and takes responsibility for the integrity of the data and the accuracy of the data analysis: $H J, J Y C$

- Study concept and design: HJ, JYC

- Acquisition of data: IGK, SHK, JJJ, LH

- Analysis and interpretation of data: IGK, SHK, JJJ, LH

- Drafting of the manuscript: HJ, JYC

- Critical revision of the manuscript for important intellectual content: EJM, BJL 
- Obtained funding: JWY

- Statistical analysis: IGK, SHK, JJJ, $L H$

- Administrative, technical, or material support: EJM, BJL

-Study supervision: JWY

\section{REFERENCES}

1. Kotekar N, Shenkar A, Nagaraj R. Postoperative cognitive dysfunction-current preventive strategies. Clin Interv Aging 2018;13:226773.

2. Vacas S, Degos V, Feng X, Maze M. The neuroinflammatory response of postoperative cognitive decline. Br Med Bull 2013;106: $161-78$.

3. Needham MJ, Webb CE, Bryden DC. Postoperative cognitive dysfunction and dementia: what we need to know and do. Br J Anaesth 2017;119:1115-25.

4. Qiao Y, Feng H, Zhao T, Yan H, Zhang H, Zhao X. Postoperative cognitive dysfunction after inhalational anesthesia in elderly patients undergoing major surgery: the influence of anesthetic technique, cerebral injury and systemic inflammation. BMC Anesthesiol 2015;15:154.

5. Alam A, Hana Z, Jin Z, Suen KC, Ma D. Surgery, neuroinflammation and cognitive impairment. EBioMedicine 2018;37:547-56.

6. Zheng XU, Ma Z, Gu X. Plasma levels of tumor necrosis factor- $\alpha$ in adolescent idiopathic scoliosis patients serve as a predictor for the incidence of early postoperative cognitive dysfunction following orthopedic surgery. Exp Ther Med 2015;9:1443-7.

7. Liu Y, Yin Y. Emerging roles of immune cells in postoperative cognitive dysfunction. Mediators inflamm 2018;18:6215350.

8. Cibelli M, Fidalgo AR, Terrando N, Ma D, Monaco C, Feldmann $\mathrm{M}$, et al. Role of interleukin- $1 \beta$ in postoperative cognitive dysfunction. Ann Neurol 2010;68:360-8.

9. Ji MH, Yuan HM, Zhang GF, Li XM, Dong L, Li WY, et al. Changes in plasma and cerebrospinal fluid biomarkers in aged patients with early postoperative cognitive dysfunction following total hip-replacement surgery. J Anesth 2013;27:236-42.

10. Altavilla D, Bitto A, Polito F, Marini H, Minutoli L, Di Stefano V, et al. Polydeoxyribonucleotide (PDRN): a safe approach to induce therapeutic angiogenesis in peripheral artery occlusive disease and in diabetic foot ulcers, Cardiovasc Hematol Agents Med Chem 2009;7:313-21.

11. Jeon JW, Lee JI, Shin HP, Cha JM, Joo KR, Kim SH, et al. Adenosine A2A-receptor agonist polydeoxyribonucleotide promotes gastric ulcer healing in Mongolian gerbils. Animal Cells Syst 2014; 18:399-406.
12. Bitto A, Polito F, Irrera N, D’Ascola A, Avenoso A, Nastasi G, et al. Polydeoxyribonucleotide reduces cytokine production and the severity of collagen-induced arthritis by stimulation of adenosine A2A receptor. Arthritis Rheum 2011;63:3364-71.

13. Ko IG, Kim SE, Jin JJ, Hwang L, Ji ES, Kim CJ, et al. Combination therapy with polydeoxyribonucleotide and proton pump inhibitor enhances therapeutic effectiveness for gastric ulcer in rats. Life Sci 2018a;203:12-9.

14. Lee J, Ahn E, Park WK, Park S. Phosphoproteome profiling of SHSY5y neuroblastoma cells treated with anesthetics: sevoflurane and isoflurane affect the phosphorylation of proteins involved in cytoskeletal regulation. PLoS One 2016;11:e0162214.

15. Zhu H, Liu W, Fang H. Inflammation caused by peripheral immune cells across into injured mouse blood brain barrier can worsen postoperative cognitive dysfunction induced by isoflurane. BMC Cell Biol 2018;19:23.

16. Huang L, Huang K, Ning H. Hispidulin prevents sevoflurane-induced memory dysfunction in aged rats. Biomed Pharmacother 2018;97:412-22.

17. Zhang YH, Guo XH, Zhang QM, Yan GT, Wang TL. Serum CRP and urinary trypsin inhibitor implicate postoperative cognitive dysfunction especially in elderly patients. Int J Neurosci 2015;125: 501-6.

18. Wang J, Su T, Liu Y, Yue Y, He R. Postoperative cognitive dysfunction is correlated with urine formaldehyde in elderly noncardiac surgical patients. Neurochem Res 2012;37:2125-34.

19. Andersson KE, Birder L. Current pharmacologic approaches in painful bladder research: an update. Int Neurourol J 2017;21:23542.

20. Song SH, Jee YS, Ko IG, Lee SW, Sim YJ, Kim DY, et al. Treadmill exercise and wheel exercise improve motor function by suppressing apoptotic neuronal cell death in brain inflammation rats. J Exerc Rehabil 2018;14:911-9.

21. Fan CH, Peng B, Zhang FC. The postoperative effect of sevoflurane inhalational anesthesia on cognitive function and inflammatory response of pediatric patients. Eur Rev Med Pharmacol Sci 2018; 22:3971-5.

22. Bjorling DE, Jacobsen HE, Blum JR, Shih A, Beckman M, Wang ZY, et al. Intravesical Escherichia coli lipopolysaccharide stimulates an increase in bladder nerve growth factor. BJU Int 2001;87:697702.

23. Haskó G, Linden J, Cronstein B, Pacher P. Adenosine receptors: therapeutic aspects for inflammatory and immune diseases. Nat Rev Drug Discov 2008;7:759-70.

24. Han JH, Jung J, Hwang L, Ko IG, Nam OH, Kim MS, et al. Anti-in- 
flammatory effect of polydeoxyribonucleotide on zoledronic acidpretreated and lipopolysaccharide-stimulated RAW 264.7 cells. Exp Ther Med 2018;16:400-5.

25. Ko IG, Kim SE, Hwang L, Jin JJ, Kim CJ, Kim BK, et al. Late starting treadmill exercise improves spatial leaning ability through suppressing CREP/BDNF/TrkB signaling pathway following traumatic brain injury in rats. J Exerc Rehabil 2018;14:327-34.

26. Park JH, Ko IG, Kim SE, Jin JJ, Hwang L, Kim CJ, et al. Dexmedetomidine oral mucosa patch for sedation suppresses apoptosis in hippocampus of normal rats. Int Neurourol J 2017;21(Suppl 1):S3947.

27. Kim YM, Jin JJ, Lee SJ, Seo TB, Ji ES. Treadmill exercise with bone marrow stromal cells transplantation facilitates neuroprotective effect through BDNF-ERK1/2 pathway in spinal cord injury rats. J Exerc Rehabil 2018;14:335-40.

28. Nagib MM, Tadros MG, Rahmo RM, Sabri NA, Khalifa AE, Masoud SI. Ameliorative effects of $\alpha$-tocopherol and/or coenzyme Q10 on phenytoin-induced cognitive impairment in rats: role of VEGF and BDNF-TrkB-CREB pathway. Neurotox Res 2019;35: $451-62$.
29. Colino-Oliveira M, Rombo DM, Dias RB, Ribeiro JA, Sebastião AM. BDNF-induced presynaptic facilitation of GABAergic transmission in the hippocampus of young adults is dependent of TrkB and adenosine A2A receptors. Purinergic Signal 2016;12:283-94.

30. Tebano MT, Martire A, Potenza RL, Grò C, Pepponi R, Armida M, et al. Adenosine A2A receptors are required for normal BDNF levels and BDNF-induced potentiation of synaptic transmission in the mouse hippocampus. J Neurochem 2008;104:279-86.

31. Minutoli L, Arena S, Bonvissuto G, Bitto A, Polito F, Irrera N, et al. Activation of adenosine A2A receptors by polydeoxyribonucleotide increases vascular endothelial growth factor and protects against testicular damage induced by experimental varicocele in rats. Fertil Steril 2011;95:1510-3.

32. Jeon SJ, Rhee SY, Ryu JH, Cheong JH, Kwon K, Yang SI, et al. Activation of adenosine $\mathrm{A} 2 \mathrm{~A}$ receptor up-regulates $\mathrm{BDNF}$ expression in rat primary cortical neurons. Neurochem Res 2011;36:2259-69.

33. Marini HR, Puzzolo D, Micali A, Adamo EB, Irrera N, Pisani A, et al. Neuroprotective effects of polydeoxyribonucleotide in a murine model of cadmium toxicity. Oxid Med Cell Longev 2018;29: 4285694. 